\title{
Transitioning to a Circular Economy: A Systematic Review of Its Drivers and Barriers
}

\author{
Jovan Tan ${ }^{1, *(\mathbb{D}}$, Fabien Jianwei $\operatorname{Tan}^{2}$ and Seeram Ramakrishna ${ }^{1} \mathbb{D}$ \\ 1 Center for Nanotechnology and Sustainability, Department of Mechanical Engineering, \\ National University of Singapore, Singapore 117575, Singapore; seeram@nus.edu.sg \\ 2 Lee Kong Chian School of Business, Singapore Management University, Singapore 178899, Singapore; \\ fabientan.2018@business.smu.edu.sg \\ * Correspondence: jovan@u.nus.edu
}

Citation: Tan, J.; Tan, F.J.;

Ramakrishna, S. Transitioning to a

Circular Economy: A Systematic

Review of Its Drivers and Barriers.

Sustainability 2022, 14, 1757. https://

doi.org/10.3390/su14031757

Academic Editor: Antonio Boggia

Received: 11 January 2022

Accepted: 1 February 2022

Published: 3 February 2022

Publisher's Note: MDPI stays neutral with regard to jurisdictional claims in published maps and institutional affiliations.

Copyright: (c) 2022 by the authors. Licensee MDPI, Basel, Switzerland. This article is an open access article distributed under the terms and conditions of the Creative Commons Attribution (CC BY) license (https:// creativecommons.org/licenses/by/ $4.0 /)$.

\begin{abstract}
Advancing societal's progress to achieve circularity is imperative as our linear (take, make, waste) economic model is highly unsustainable. It depletes our natural resources and substantially contributes to pollution and global greenhouse gas emissions. Our continued participation in the linear economy will also expose businesses to volatile resource prices and supply disruptions resulting from the scarcity of critical materials and geopolitical factors. Hence, there are compelling reasons for businesses to transit and participate in the circular economy. However, anecdotal evidence suggests limited practical implementations. Therefore, this systematic review aims to determine the most significant drivers and barriers that influence business leaders to transform their businesses for participation in the circular economy. By clarifying the most influential factors and their characteristics, we can introduce effective measures to encourage or mitigate them. This review takes a transdisciplinary approach to discuss salient and consequential ideas with depth and completeness. Its associated practical and managerial implications are also thoroughly discussed.
\end{abstract}

Keywords: circular economy; sustainable development; sustainability; drivers; barriers; review

\section{Introduction}

In August 2021, the Intergovernmental Panel on Climate Change (IPCC) published the first of three major reports that constitute its Sixth Assessment Report. It revealed that humanity is perilously close to the internationally agreed threshold of 1.5 degrees Celsius and calls for immediate and collective action to reduce reliance and use of fossilfuel-based energy systems expeditiously [1]. Assuming society unanimously responds to IPCC's appeal and only uses zero-carbon energy sources from this point onwards, does that definitively mean society will be able to limit its global temperature rise to 1.5 degrees Celsius?

We think that is improbable as the Ellen MacArthur Foundation [2] estimates that the decarbonization of our energy systems can only eradicate up to $55 \%$ of global greenhouse gas (GHG) emissions. The remaining $45 \%$ originates from industrial activities such as extracting raw materials, producing goods, and land management. Emissions arising from these constituents must be comprehensively addressed if humanity is sincere in achieving our global temperature targets. Unfortunately, GHG emissions from these activities are not expected to slow down soon, given that society still predominantly operates in a highly unsustainable linear (take, make, waste) economic model.

In 2017 alone, we have extracted almost three and a half times more natural resources from Earth's surface than in 1970, and it is expected to double by 2060 [3]. Conversely, only $8.6 \%$ of the astronomical amount of resources we have extracted today are recycled to close the loop, which is $0.5 \%$ lesser than in 2018 levels [4]. Hence, if this continues, our global waste production levels in 2050 will rise by $70 \%$ more than today's levels [5]. Eventually, 
this widening disparity between extraction and recovery will exhaust all of Earth's natural resources and induce irrevocable environmental damage [6].

Beyond ecological implications, our continued participation in the linear economy will also expose businesses to volatile resource prices and supply disruptions resulting from the scarcity of critical materials and geopolitical factors [7,8]. Even before the COVID-19 pandemic, Allianz Global Corporate \& Specialty [9] has consistently ranked business interruptions, including supply disruptions, as one of the top business risks. For that reason, it would be in any businesses' best interest to proactively cease its participation in the linear economy and transit towards a more sustainable economic model [10,11]. A more sustainable economic model would be the circular economy model, where the industrial system is restorative or regenerative by intention and design [12].

The transition towards circularity presents a multitude of benefits for businesses. In their pursuit, businesses endeavor to effectively eliminate waste and pollution by designing their products for reusability, recyclability, and industrial symbiosis. Hence, the deliberate effort to transit towards a circular economy would naturally present businesses with the opportunity to holistically review and reduce their environmental footprint and operational waste while optimizing how their valuable resources should be used [13]. It further allows businesses to innovate and create new value propositions to appeal to increasingly conscientious consumers seeking alternatives for a greener, cleaner, and more equitable lifestyle $[11,14,15]$. However, anecdotal evidence suggests limited practical implementations despite its attractive proposition, as evident by the low and declining global resource recovery rate.

Despite many advancements in circular economy research, there is still no clear and conclusive explanation for this conundrum. Some scholars hypothesized that the hurdles are technological, while others argued they were economical or physiological. We believe it is a complex mix of several distinct factors, where some accelerate a business's progress towards circularity while others impede. Furthermore, our fast-changing world constantly challenges the validity of these established factors. For that reason, we believe it is necessary to comprehensively and systematically review the current state of knowledge to determine: "What are the key drivers and barriers influencing business leaders in their decision to transform their businesses for participation in the circular economy?" Addressing this research question is the objective of this review. It is imperative to clarify the most influential factors today before we can devise and introduce effective measures to either encourage or mitigate them.

\section{Methodology}

We adopted the five-step method proposed by Khan, et al. [16] to construct and present our systematic review. Among the numerous systematic review methodologies we have evaluated, we found the five-step method to be the most applicable without compromising the review's replicability, credibility, and transparency. The five steps include (1) framing the question for review, (2) identifying relevant work, (3) assessing the quality of studies, (4) summarizing the evidence, and (5) interpreting the findings.

Firstly, to reiterate, our research question is: "What are the key drivers and barriers influencing business leaders in their decision to transform their businesses for participation in the circular economy?" Next, to identify quality and relevant work for our review, we searched refereed articles, books, policy papers, and other authoritative works across both scholarly and non-scholarly platforms. We limited our search to works presented in English and published from 2016 onwards. We further narrowed it to highly cited works with at least 50 citations for those published between 2016 and 2020 and at least 10 citations for those published in 2021.

"Drivers" and "Barriers" are metonyms that generally refer to factors with positive or negative influence on a particular subject, respectively. Accepted synonyms for "Drivers" in the context of our research include accelerators, enablers, and opportunities, while accepted synonyms for "Barriers" include constraints, challenges, and obstacles. To ensure we 
achieved our desired results, we tested multiple combinations of synonyms and randomly examined up to 10 of the most relevant works from each combination across various platforms. We reiterated the process to optimize for a representative set of search terms. We eventually settled for the search terms "driver", "enable*", and "opportunit" to represent "Drivers", and "barrier" ", "challenge*", "obstacle*" to represent "Barriers". We also added the contextual search term "Circular*" - which considers "circular economy", "circular", and "circularity".

Accordingly, we executed the following boolean syntax on the title, abstract, and keywords: (barrier* OR challenge* OR obstacle ${ }^{*}$ AND (driver* OR enable* OR opportunit*) AND (Circular*) which yielded a total of 3737 publications across Scopus $(n=1862)$, Dimensions $(n=726)$ and Web of Science $(n=1149)$. After applying our delineated date range and citation criteria, we arrived at a total of 287 publications across Scopus $(n=123)$, Dimensions $(n=88)$, and Web of Science $(n=76)$. Next, we screened the list and eliminated duplicated entries. Lastly, we scrutinized the remaining works and selected 51 contributions to answer our research question. Of these 51 contributions, we included four articles that did not qualify based on our criteria yet offered valuable insights from a territorial and industry perspective. Figure 1 illustrates our search strategy to acquire the relevant and quality works for this review. The complete list of all the included and analyzed works and the reasons for their inclusion are available as Supplementary Material.

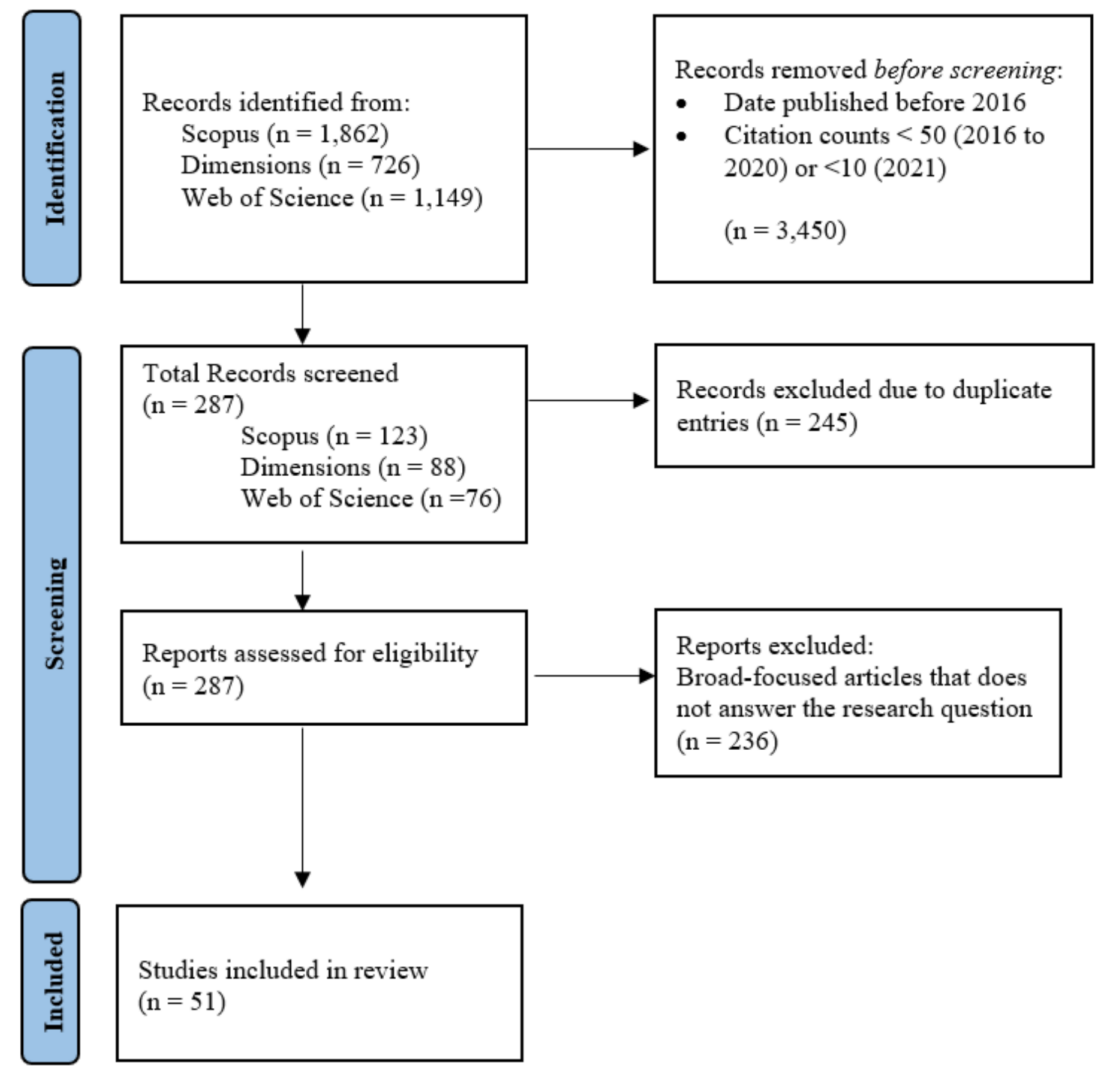

Figure 1. Search Strategy Flow Diagram.

\section{Characteristics of Included Works}

For the original research articles we included, we observed a significant inclination for scholars to investigate the drivers and barriers through the lens of small and mid-sized businesses. Scholars are attracted to understanding these demographics' representatives' perspectives and decision-making considerations. From the posture of their works, we deduced that perhaps scholars might have easier access to their ideal representatives from small and mid-sized businesses than larger organizations. Anecdotally, we presumed the insights derived from these selected demographics are more valuable than platitudes from 
larger organizations. Additionally, we suspect that larger organizations may be reluctant to participate in these research studies due to the sensitive nature of business information.

In other works, including authoritative grey literature and review articles, we noticed two distinct styles of discussing the drivers and barriers. The first discussion style is broad and shallow. We noticed it is predominantly present in thematic analyses and works that try to conform and neatly assign their pointers to drivers or barriers. This presentation style contains repetitive points to help readers make sense of the findings and interpretations. It also lacks coherence and depth as authors trim and attune their discussion pointers to fit within the scope of their presented header. The other discussion style is extensive but singularly focused on a particular subject. These works are mainly review articles presented in academic journals, and the writings are scoped appropriately to the aims and scopes of the publication. The main drawbacks of these works are their monodisciplinary approach-for example, focusing only on materials in the circular economy. While the discussed points were thorough, they were not holistic as works from other disciplines were neglected. Therefore, to meaningfully contribute to advancing the body of knowledge, we decided to take a transdisciplinary approach to discuss the salient and consequential ideas with depth and completeness. We will then delve into our insights' practical and managerial implications and provide our recommendations.

\section{Results and Discussions}

\subsection{Intention-Action Gap}

Our review found consumers" "intention-action gap" a significant socio-cultural barrier. Consumers play a more prominent role in societal's progress towards achieving circularity than they think. Tan and Cha [14] demonstrated that consumers inherently desire a healthier lifestyle, be more humane, and protect the environment. Hence, the more they are aware, interested, and genuinely concerned with current and emerging environmental sustainability issues, the higher likelihood they will seek to adopt cleaner, greener, and more sustainable alternatives over mass-market solutions [17-22]. For that reason, scholars asserted the pressing need for more public awareness campaigns in urgent environmental sustainability issues, including waste pollution and the perils of the linear economy $[11,19,23,24]$.

However, while awareness precedes actions, being aware does not definitively translate into action. Our review found that consumers are not always seen putting their words into action despite voicing their support for a more sustainable alternative. Scholars have termed this contradictory behavior an "intention-action gap" and stressed the importance of narrowing it to meet corporate sustainability goals and avert potential setbacks to collective societal progress towards circularity. The food services industry (FSI) is a good case in point. It was observed that consumers' "intention-action gap" left progressive FSI establishments divided on taking on the additional cost of adopting more sustainable food packaging options [25]. IKEA's recently concluded research in 30 markets also shares the same sentiments. It concluded that out of the $70 \%$ of respondents who are "deeply concerned" with climate change, only $3 \%$ are prepared to pay for environmentally friendly products [26]. White, et al. [27] also noted in their work that only a quarter of the $65 \%$ of survey respondents who expressed their intent to buy from sustainable and purpose-driven brands do so.

White et al. further suggested a variety of marketing-based tactics, including using social influence, to encourage elusive green consumers to align their consumption with their stated preferences and close the intention-action gap. However, employing these tactics alone is ineffective. It needs to be coupled with improving consumers' perceptions of sustainable alternatives and reducing its green premium. If consumers do not positively perceive greener products, they will have fewer incentives to participate. To illustrate, in the case of recycled products, Bigliardi, et al. [28] found that some consumers perceived recycled merchandise as second-hand goods and expressed safety concerns in using them and low confidence in their quality. Skard, et al. [29] further noted these observations to 
be more prominent in strength-related products. They found that consumers typically associate a green strength-related product with functional inferiority, even if its green attributes have no direct link to the core product performance. For example, truck drivers were skeptical about using recycled tires as they assumed their durability and effectiveness were inferior to their non-recycled counterparts [30].

Additionally, as we briefly alluded to earlier, reducing the green premiums of these products is a critical success factor in closing the intention-action gap. Tan and Cha [14] found that consumers were willing to switch to greener products if the green premiums were not more than $50 \%$ over mass-market alternatives. However, today's surveyed prices for greener products tend to exceed or be closer to the upper bound of the consumer's acceptable price range. The stark price differences can be explained by scarcity, resource limitations, and inherent production and operational inefficiencies [14]. Furthermore, in the case of a linear production system, Pheifer [31] argues that the absence of pricing externalities allowed mass-market products to be produced at a low cost. Virgin plastics are a good case in point $[32,33]$. There are differences between returns or costs to private entities and society by not pricing in the externalities. In the case of pollution, a classic example of a negative externality, pricing decisions were made based only on the direct cost of and profit opportunity from production, with no consideration to the indirect costs to those harmed by the pollution [34].

\subsection{Risk Attitudes}

Risk attitudes are another salient socio-cultural barrier. At an organizational level, we found that most leaders in small and mid-sized enterprises are risk-averse to making changes $[11,15,22]$. These risk-averse behaviors led leaders to instinctively create avoidable inertia that impedes them from taking the necessary action to transform their businesses for participation in the circular economy. As a result, their decisions and actions cascade throughout the organization and stymie its innovativeness and progress towards circularity [35]. Unremarkably, these observations of conformity are also observed and consistent with the organizational behavior and behavioral economics literature. The level of risk aversion is well supported by Daniel Kahneman's Prospect Theory [36] which outlines an individual's decision-making behavior under risks. The theory's certainty effect demonstrates that gains are overvalued, and losses are undervalued. Therefore, in a mix of gain and loss domains, individuals tend to be risk-avoidant and maintain the status quo in any scenario with equivalent gains until a more promising alternative arises.

We ascertained that two distinct forces could further amplify risk aversion in business leaders. First, in today's VUCAH (volatility, uncertainty, complexity, ambiguity, and hyperconnectivity) world, information is constantly updated in real-time and is freely available and accessible on-demand [37]. This neverending flow of new information increased uncertainty and complexity in the business environment. As a result, this led business leaders to suffer from analysis paralysis, which intensified and perpetuated their risk aversion to changes, despite its benefits. Next, Arkes \& Blumer's Sunk Cost Fallacy [38] further solidifies risk aversion in business leaders. The fallacy describes "a tendency to continue an endeavor once an investment of time, effort, or money has been made." This behavior is generally irrational, and it reinforces the mental state that past arrangements heavily influence future decisions.

As we have previously discussed, businesses' commitment to participate in the circular economy would foreseeably entail considerable effort and resources to pivot away from their existing linear-centric operations. Even if businesses have the resources and capabilities to do so, it is conceivable that they would prefer maximizing the useful life of their existing systems until the inevitable happens, ceteris paribus. In more extreme cases, risk-aversed business leaders are also observed to reject the idea of sustainability and circularity altogether [39]. When seeking collaborations with stakeholders within their value chain, risk-aversed business leaders also tend to be met with an ambivalent response [40,41]. Oghazi and Mostaghel [22] suggest that their stakeholders are afraid of 
potential trust issues during collaboration, such as ignoring mutual benefits and disrespecting the confidential nature of business information, as risk-averse leaders are typically not ideal collaborators.

\subsection{Policy Actions}

Policy refers to the law, regulation, procedure, administrative action, incentive, or voluntary practice of governments and other institutions. They can be both punitive and supportive. Punitive measures deter undesirable behaviors and promote responsible consumption and production. We infer from our review that a comprehensive and wellimplemented punitive measure can be a powerful regulatory driver. For instance, in the United States of America and China, companies operating in these territories can be subjected to financial penalties should they choose to dispose of unsought yet usable materials instead of recycling or re-manufacturing them $[19,24]$. However, there is presently a dearth of such holistic punitive measures to advance the circular economy.

Today, most measures merely address waste and pollution issues. For example, organizations and their directors can be subjected to hefty taxes, fines, or even imprisonment in most jurisdictions if they are caught polluting the environment $[10,23]$. Ferronato and Torretta [42] noted that such punitive measures could also spur significant organic societal changes in developing countries, given certain preconditions. For instance, businesses operating in these vicinities were seen to enlist the help of the low-income communities to sort their waste manually. Both parties found attractive propositions to collaborate. Firstly, the low-income communities can earn a living through these manual waste sorting tasks. At the same time, businesses that were required to comply with the national waste pollution regulations were motivated by the cost savings of engaging these low-income communities compared to regular recycling services. As a result of this interaction, the locality saw reduced labor issues and an increased recycling rate, which is advantageous towards achieving a circular economy.

As for supportive measures, the most common forms of legislation and policies are grants, rewards, financial aid, and subsidies. As we have previously discussed, due to various socio-cultural barriers, businesses would prefer maximizing the useful life of their existing linear-centric systems until the inevitable happens or until a more promising alternative arises. Hence, robust supportive measures that can ease a businesses' financial burden and amplify stakeholder alignment efforts would encourage them to switch. This makes government support a pivotal regulatory driver. Unfortunately, our review found present-day government support to be sorely inadequate $[11,15,19,20,22,24,41,43]$.

Our review further suggests that present-day supportive measures tend to be slow to introduce, uncoordinated, and fail to address on-the-ground concerns. All of which resulted from the (a) incoherent implementation of government support across various agencies, the (b) lack of effective communication channels and flow of information between stakeholders and their government, and (c) obstructive law and complex legal and administrative procedures $[11,35,43]$. Presently, the inability of waste to cross international borders for treatment, despite involved parties reasonably demonstrating how the waste can achieve circularity if treated by the appointed foreign waste treatment facility, is an example of current obstructive law.

Nonetheless, in an ideal scenario where the impediments are eliminated and symbiotic punitive and supportive measures are extensively considered, we can expect policy action to accelerate societal progress towards achieving circularity exponentially. The success of Germany's Closed Cycle Management Act is a case in point. It introduced a suite of complementary targeted policies to transit the society to participate in the circular economy. For example, it transposed the "waste hierarchy" in Article 4 of the revised European Union Waste Framework Directive (Directive 2008/98/EC) into German law. Additionally, it made waste prevention policies, targets, and measures more accountable and transparent to the general public. It clearly defined the role and responsibilities of municipal and private waste management companies, respectively, and strictly adhered to a "polluter- 
pays" principle, where the producer has to pay for waste treatment or disposal without any government subsidies. As a result, these collective efforts helped Germany inch closer to achieving a circular economy with high recycling rates of $60 \%$ municipal waste, $60 \%$ commercial waste, and 90\% construction and demolition waste [44].

\subsection{Technology, Knowledge and Infrastructure}

As discussed in the earlier section, robust policy actions can stimulate technological advancements, knowledge sharing, and the establishment of critical ecosystem infrastructures. These elements are imperative but, presently, severely inadequate. As a result, our included works characterized them as a significant barrier, though they underscored its latent potential as a prevailing driver.

A salient barrier within this group is the lack of expertise in the circular economy. This includes deep domain knowledge, technical know-how to shift from linear to circular product life cycles-for example, defining a circular business strategy, product design, and material flow-and other relevant insights [45]. As the concept of circularity is still relatively nascent, several works demonstrated that while businesses have a general idea of what it entails, only a handful of them have the necessary knowledge and expertise to appropriately transform their businesses for participation in the circular economy $[10,11,15,19,20,24,39-41,43,46,47]$. Consequently, business leaders pursued deficient strategies that are not always aligned with circular economy principles and could even be controversial at times. For example, many businesses considering incorporating biodegradable plastics in their product offerings lack the necessary knowledge to ascertain if its adoption would genuinely advance their circularity agendas. Instead, they merely adopted biodegradable plastics due to the intrinsic motivation of business leaders to want to do good and the positive public perception. As a result, their course of action may inadvertently complicate downstream recycling processes as commonly used biodegradable plastics, such as polylactic acid (PLA) and polyhydroxyalkanoates (PHA), are advised to be treated separately from their fossil fuel-based counterparts. However, it is impossible to discriminate visually when both materials are co-mingled in the same waste stream as they possess similar resemblances and properties [25,48].

There is also a cost for businesses to acquire and continuously upkeep their technology and expertise [40]. While several businesses may not have the financial appetite or will to acquire it, De Jesus and Mendonça [10] and Hart, et al. [49] argued the importance for them to acquire it at some point. This allows them to pursue viable opportunities and share their expertise internally and across the value chain to keep critical stakeholders aligned. Rizos, et al. [15] and Tura, et al. [11] further argue that knowledge sharing between firms can foster greater collaborations, boost research and development efforts, and encourage innovative endeavors. However, not all firms agree with this proposition. Several works noted that firms with domain knowledge and technological expertise are unwilling to share as they value it as their competitive advantage $[20,21,50]$. By exclusively holding on to it, they can maximize their profit extraction. Hence, if such homo economicus perspective and behavior persist, businesses and their leaders will essentially follow profit-maximizing goals and put those ahead of any other goals [51]. This leads to the expertise gap between firms gradually widening, despite all parties pursuing the same circularity ambition. Consequently, such behaviors will transpire and affect the establishment of critical ecosystem infrastructures that need to be in place for a smooth transition [45]. These ecosystem infrastructures relate to the product's life cycle, including waste management, treatment facilities, packaging, recycling processes, and more.

We can use the food services industry to illustrate the importance of managing the dynamics of this group of elements. Firstly, the waste produced by the FSI establishments is primarily a mix of food waste and food packaging waste. This packaging waste stream is highly contaminated, so neatly segregating it for traditional recycling is impossible. Thus, any form of material recovery is limited, so foodservice waste is often incinerated or dumped in a controlled environment. Despite these circumstances, Tan, Tiwari and 
Ramakrishna [25] argued for the technical possibility of foodservice waste achieving circularity using bio-based biodegradable materials, organic recycling, and industrial symbiosis (Figure 2). However, they expound and emphasize that unless certain preconditions are satisfied, truly achieving circularity in the FSI remains a distant dream. These preconditions include establishing a self-sustaining and economically viable waste treatment and industrial symbiosis ecosystems, among others. Therefore, at the very least, firms and other key stakeholders, including the governments, need to collectively support one another in introducing these critical elements and putting them in place to facilitate a circular flow of materials.

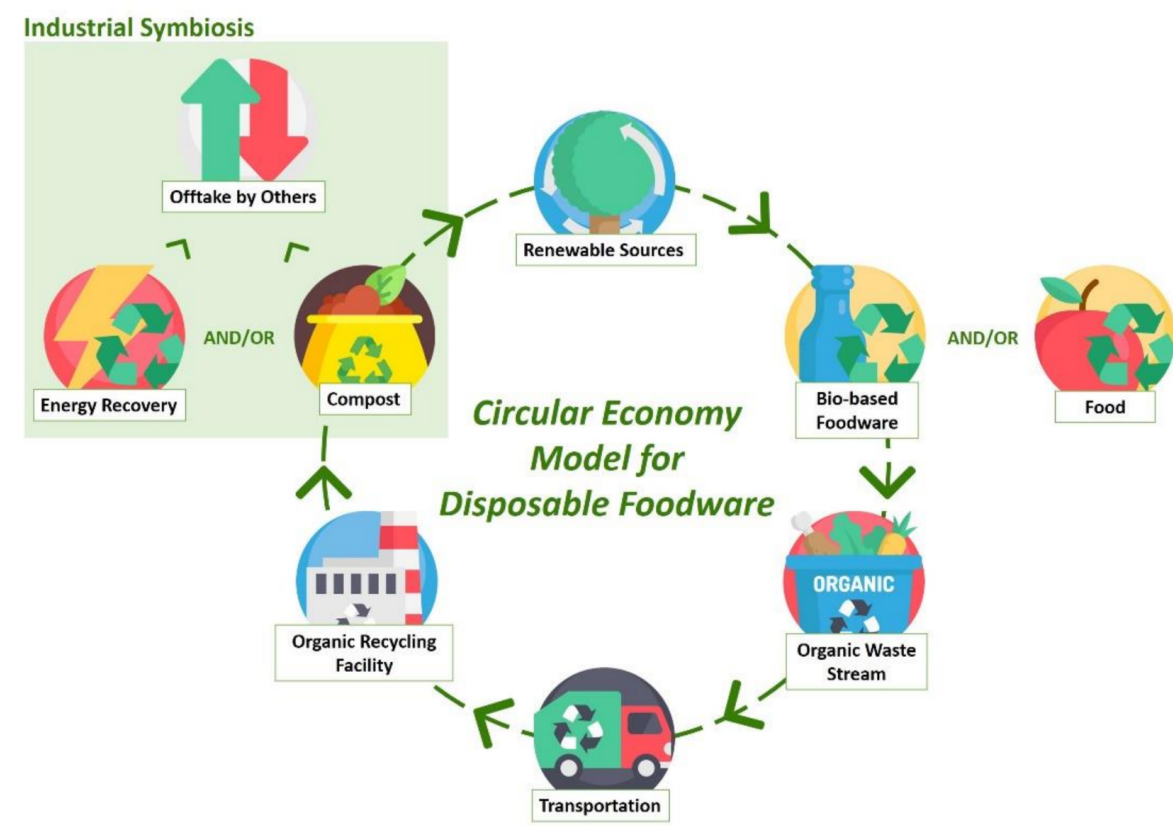

Figure 2. Circular Economy Model for Disposable Foodware in the Food Services Industry. Reproduced with permission from Tan, Tiwari and Ramakrishna [25], Single-Use Plastics in the Food Services Industry: Can It Be Sustainable?, published by Springer Nature, 2021.

\section{Practical and Managerial Implications and Recommendations}

Examining the body of knowledge through a transdisciplinary lens allowed us to identify and discuss salient yet often unexplored themes in-depth. The interactions of these themes, either singly or collectively, have significant implications for circular economy research and practice. With some clarity and understanding of these influential drivers and barriers, we offer our perspectives on mitigating their adverse effects and encouraging their positive ones.

\subsection{Consumer Education}

Earlier, we determined consumers' intention-action gap as a significant socio-cultural barrier. We identified the consumers' perceptions of sustainable alternatives and their green premium as the root cause. For that reason, we recommend that business leaders pursue effective public education campaigns to address any negative perceptions of their sustainable alternatives. This recommendation contradicts the need to drive greater public awareness on pressing sustainability issues, which was initially prescribed by our included works. We made this recommendation as the intention-action gap denotes that consumers today are already sensitive to current and emerging environmental sustainability issues to the extent that they desire cleaner, greener, and more sustainable alternatives wherever possible. Therefore, we firmly believe strategic public education will be more advantageous in influencing consumers' perception of the sustainable alternative by providing facts, clarifying its performance and benefits, and justifying its green premium. Beyond public education, we further urge business leaders to continue pursuing and employing other 
effective avenues to engage and positively encourage their prospective users to adopt their solutions.

\subsection{Embracing Restorative Innovation}

For reducing the green premiums of their sustainable alternatives, we encourage business leaders to embrace the Restorative Innovation model by Tan and Cha [14]. The model demonstrates how the cost of sustainable alternatives can decline due to cumulative production. An impact-driven perspective must be upheld for the sustainable alternative to follow the model's described growth pattern. This means the business leader must prioritize impact translation over mere profit generation. This is critical as the essence of the Restorative Innovation model necessitates that as the impact-driven leaders scale up their businesses, they faithfully reinvest their profits to (a) increase their product availability and capacity, (b) eliminate inherent inefficiencies, and (c) optimize their supply chain. Pursuing these strategies allows them to achieve economies of scale and operate more efficiently. This enables them to gradually reduce the cost of their innovative solutions and use the savings to offset and reduce the green premium to a price range acceptable by mass consumers. Figure 3 illustrates the Restorative Innovation model to help readers visualize the growth pattern of these sustainable alternatives.

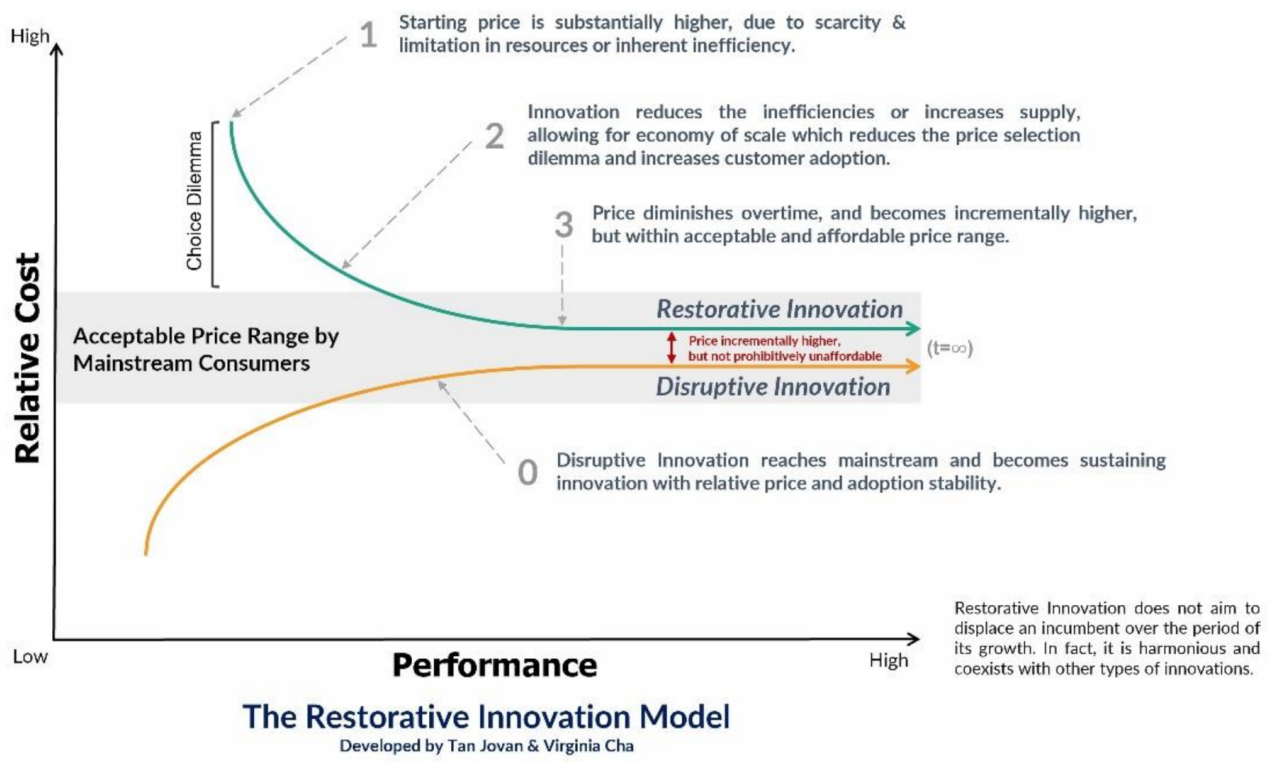

Figure 3. Restorative Innovation Model. Adapted with permission from Tan, J. and Cha, V. [14], Innovation for Circular Economy; published by Springer Nature, 2021.

\subsection{Level the Playing Field}

A persistent theme from our analysis is the observed disparity within topics of interest. The first disparity relates to the cost of mass production of goods through a linear production system. It is often cheaper than a circular production system, as the negative externalities on society, the environment, and the economy were not internalized. Virgin hydrocarbon plastics production is a good case in point. DeWit, et al. [33] estimated that the actual cost of plastic to the environment and society could be at least ten times higher than the market price paid by primary plastic producers. By 2040, this figure could double unless there are urgent interventions. Due to the current pricing structure, buyers have fewer economic incentives to switch to more sustainable alternatives, thereby impeding circularity efforts [32] and allowing GHG from extracting raw materials, which should not be produced, to be produced.

The second disparity involves the lack of standard evaluation criteria to assess businesses' progress to achieving circularity. While businesses must innovate and differentiate themselves from their competitors, their progress towards achieving circularity must be 
evaluated on the same set of indicators-for example, product and material flow-related indicators. Tura, et al. [11] suggest aligning their assessments with standards, which are agreed on formulas that describe the best way of doing something. We agreed, and we further believe standards can also communicate best practices and bridge the knowledge gap we identified in Section 4.4. However, as circular economy research and practice are relatively nascent, these standards are still being developed. We need these standards to be widely adopted to level the playing field.

State-initiated reward and recognition programs are supportive measures that can also be alternate mechanisms to align a business's progress to prescribed indicators. The Green Mark certification scheme by Singapore's Building and Construction Authority is an exemplary program encouraging sustainable practices in the building sector. It was introduced in 2005, and it provides a comprehensive framework for assessing the overall environmental performance of new and existing buildings. Additionally, it rates the building's performance based on its comprehensive framework and recognizes outstanding achievers with certificates and cash awards. By the end of 2020 , more than $43 \%$ of the total gross floor area of Singapore's building stock met the Green Mark standards, with each building estimated to save up to 40 percent energy across its lifetime [52]. Presently, to the best of our knowledge, there are no similar programs designed to accelerate the societal transition to a circular economy, and we highly recommend establishing one. Furthermore, well-designed reward and recognition programs can effectively counter risk aversion in business leaders, a significant socio-cultural barrier we identified earlier, and encourage them to take a step in the right direction $[20,39]$.

We admit policy intervention, not a business decision, is likely the only way to mitigate these systematic issues and level the playing field. We do not expect them to be resolved soon, but we chose to communicate it as there are significant practical implications. Leaders must understand that (a) achieving fairer unit economics among materials and production methods and (b) aligning the assessment of their progress with other ecosystem players, including their competitors, are imperative for society to advance towards a circular economy collectively.

\subsection{Stakeholder Alignment}

Our last recommendation is stakeholder alignment. Our analysis suggests that it can resolve multiple salient barriers. Multiple works noted that aligned stakeholders could foster impactful collaborations and pressure external ecosystem players to participate in broader circularity efforts $[39,49,53]$. The observation on organic societal action by Ferronato and Torretta [42] earlier is a case in point. As a result of external stakeholder alignment, there could be knowledge and technology sharing between firms if interest aligns. By extension, it could also enable the establishment and proliferation of critical ecosystem infrastructures needed to facilitate a circular flow of materials.

Within the organization, aligned stakeholders, especially shareholders, can support the business's transition to participate in the circular economy by encouraging and empowering appointed executive leaders to take the long view and pursue complementary strategies. Doing so could remedy risk aversion in business leaders. It could also mitigate a worrisome observation that when business leaders are confronted with prioritizing profits or achieving their sustainability objectives, they will favor short-term profits, despite knowing that achieving the latter yields greater rewards in the long term [15,40,41,51].

\section{Conclusions}

This systematic review comprehensively evaluated the current circular economy literature to determine the most significant drivers and barriers that influence business leaders in their decision to transform their businesses for participation in the circular economy. It is imperative to clarify the most influential factors today and their characteristics before we can devise and introduce effective measures to encourage or mitigate them. Our transdisciplinary review holistically discussed salient ideas with depth and completeness. 
We found these ideas to be (a) influential by themselves, (b) have significant implications if left neglected, and (c) could severely deter a firm's progress to achieving circularity if they interact.

Among our presented factors, we found risk aversion by business leaders to be the most troubling. As decision-makers, risk-averse leaders can significantly impede any internal progress to achieve circularity or reject the idea entirely. They are observed to be reluctant to participate in the circular economy unless the inevitable happens. Additionally, they favor short-term profit to achieving their sustainability goals if given an option. If such behavior persists, it can stymie their firm's innovativeness and collaborative potential. While there are significant implications if left neglected, risk aversion is fundamentally physiological and within the control of the affected party. Stakeholder alignment, especially amongst shareholders, effectively remedies risk aversion by encouraging and empowering appointed executive leaders to take the long view and pursue complementary strategies.

Conversely, the most significant driver would be a comprehensive and well-executed suite of policy actions to encourage the transition to the circular economy. Punitive measures can deter undesirable behaviors, while supportive measures can strongly encourage businesses to take the first transitional step to a circular economy. However, society needs more supportive measures from their local policymakers as our review concludes that present-day measures are severely lacking. For these measures to be well-designed and achieve their intended purpose, it needs to meticulously address the root cause, be synergistic with other policy actions and be non-obstructive. It also needs to be fast, simple, and easy for businesses to participate and benefit. More importantly, policy actions can and must be used to facilitate the development and sharing of technology, knowledge, and infrastructure among ecosystem players. Ultimately, the establishment of critical ecosystem infrastructures and expertise is needed to facilitate a circular flow of materials.

Last but not least, we recommend businesses to sincerely focus on consumer education of their products over raising awareness on broad sustainability issues. We further recommend that they embrace the Restorative Innovation model to lower the green premiums of their sustainable alternatives. We further encourage the enactment of targeted policy actions to level the playing field by (a) reducing cost disparities between a linear and circular production system and (b) standardizing the evaluation criteria to assess a business's progress towards circularity. A state-initiated reward and recognition program can serve as an alternate mechanism to align a business's progress to desired prescribed indicators.

Supplementary Materials: The following supporting information can be downloaded at: https: / / www.mdpi.com/article/10.3390/su14031757/s1, List of Included Works—list of documents used in the study.

Author Contributions: Conceptualization, J.T.; methodology, J.T.; formal analysis, J.T. and F.J.T.; investigation, J.T. and F.J.T.; resources, J.T. and S.R.; writing—original, J.T. and F.J.T.; writing—revision and editing, J.T.; writing-review and editing, S.R.; supervision, S.R. All authors have read and agreed to the published version of the manuscript.

Funding: This research received no external funding.

Institutional Review Board Statement: Not applicable.

Informed Consent Statement: Not applicable.

Data Availability Statement: The complete list of all the included and analyzed works and their reasons for inclusion are available in the Supplementary Materials. All other data are contained within the article.

Acknowledgments: J.T. would like to acknowledge the support provided by the NUS Research Scholarship (GRSUR5000001 Res Sch (PhD) SERIS SC) during the period of his study.

Conflicts of Interest: The authors declare no conflict of interest. 


\section{References}

1. IPCC. Climate Change 2021: The Physical Science Basis. Contribution of Working Group I to the Sixth Assessment Report of the Intergovernmental Panel on Climate Change; Intergovernmental Panel on Climate Change: Geneva, Switzerland, 2021.

2. Ellen MacArthur Foundation. Completing the Picture: How the Circular Economy Tackles Climate Change; Ellen MacArthur Foundation: Cowes, UK, 2019.

3. International Resource Panel. Global Resources Outlook 2019: Natural Resources for the Future We Want; United Nations Environment Programme: Nairobi, Kenya, 2019.

4. Haigh, L.; de Wit, M.; von Daniels, C.; Colloricchio, A.; Hoogzaad, J.; Fraser, M.; Sutherland, A.B.; McClelland, J.; Morgenroth, N.; Heidtmann, A. The Circularity Gap Report 2021; Ruparo: Amsterdam, The Netherlands, 2021.

5. Kaza, S.; Yao, L.C.; Perinaz, B.-T.; Van Woerden, F. What a Waste 2.0: A Global Snapshot of Solid Waste Management to 2050; World Bank: Washington, DC, USA, 2018.

6. Farooque, M.; Zhang, A.; Thürer, M.; Qu, T.; Huisingh, D. Circular supply chain management: A definition and structured literature review. J. Clean. Prod. 2019, 228, 882-900. [CrossRef]

7. Circle Economy; PGGM; KPMG; European Bank for Reconstruction and Development (EBRD); World Business Council For Sustainable Development (WBCSD). 'Linear Risks': How Business as Usual Is a Threat to Companies and Investors; Ruparo: Amsterdam, The Netherlands, 2018.

8. Ellen MacArthur Foundation. Towards the Circular Economy; Ellen MacArthur Foundation: Cowes, UK, 2013.

9. Allianz Global Corporate \& Specialty. Allianz Risk Barometer: Identifying the Major Business Risk for 2021; Allianz Global Corporate \& Specialty SE: Munich, Germany, 2021.

10. De Jesus, A.; Mendonça, S. Lost in Transition? Drivers and Barriers in the Eco-innovation Road to the Circular Economy. Ecol. Econ. 2018, 145, 75-89. [CrossRef]

11. Tura, N.; Hanski, J.; Ahola, T.; Ståhle, M.; Piiparinen, S.; Valkokari, P. Unlocking circular business: A framework of barriers and drivers. J. Clean. Prod. 2019, 212, 90-98. [CrossRef]

12. Selvan, R.T.; Ramakrishna, S. Sustainability for Beginners; World Scientific: Singapore, 2021; p. 200. [CrossRef]

13. Atasu, A.; Dumas, C.; Wassenhove, L.N.V. The Circular Business Model. Harvard Business Review. July-August 2021. Available online: https:/ /hbr.org/2021/07/the-circular-business-model (accessed on 11 November 2021).

14. Tan, J.; Cha, V. Innovation for Circular Economy. In An Introduction to Circular Economy; Springer: Singapore, 2021; pp. 369-395.

15. Rizos, V.; Behrens, A.; Van Der Gaast, W.; Hofman, E.; Ioannou, A.; Kafyeke, T.; Flamos, A.; Rinaldi, R.; Papadelis, S.; HirschnitzGarbers, M.; et al. Implementation of Circular Economy Business Models by Small and Medium-Sized Enterprises (SMEs): Barriers and Enablers. Sustainability 2016, 8, 1212. [CrossRef]

16. Khan, K.S.; Kunz, R.; Kleijnen, J.; Antes, G. Five steps to conducting a systematic review. J. R. Soc. Med. 2003, 96, 118-121. [CrossRef]

17. Barros, M.V.; Salvador, R.; Do Prado, G.F.; De Francisco, A.C.; Piekarski, C.M. Circular economy as a driver to sustainable businesses. Clean. Environ. Syst. 2021, 2, 100006. [CrossRef]

18. Kalmykova, Y.; Sadagopan, M.; Rosado, L. Circular economy-From review of theories and practices to development of implementation tools. Resour. Conserv. Recycl. 2018, 135, 190-201. [CrossRef]

19. Govindan, K.; Hasanagic, M. A systematic review on drivers, barriers, and practices towards circular economy: A supply chain perspective. Int. J. Prod. Res. 2018, 56, 278-311. [CrossRef]

20. Ormazabal, M.; Prieto-Sandoval, V.; Puga-Leal, R.; Jaca, C. Circular Economy in Spanish SMEs: Challenges and opportunities. J. Clean. Prod. 2018, 185, 157-167. [CrossRef]

21. Mangla, S.K.; Luthra, S.; Mishra, N.; Singh, A.; Rana, N.P.; Dora, M.; Dwivedi, Y. Barriers to effective circular supply chain management in a developing country context. Prod. Plan. Control 2018, 29, 551-569. [CrossRef]

22. Oghazi, P.; Mostaghel, R. Circular Business Model Challenges and Lessons Learned-An Industrial Perspective. Sustainability 2018, 10, 739. [CrossRef]

23. Fan, Y.V.; Lee, C.T.; Lim, J.S.; Klemeš, J.J.; Le, P.T.K. Cross-disciplinary approaches towards smart, resilient and sustainable circular economy. J. Clean. Prod. 2019, 232, 1482-1491. [CrossRef]

24. Min, Z.; Sawang, S.; Kivits, R.A. Proposing Circular Economy Ecosystem for Chinese SMEs: A Systematic Review. Int. J. Environ. Res. Public Health 2021, 18, 2395. [CrossRef]

25. Tan, J.; Tiwari, S.K.; Ramakrishna, S. Single-Use Plastics in the Food Services Industry: Can It Be Sustainable? Mater. Circ. Econ. 2021, 3, 1-16. [CrossRef]

26. Biekert, M. Ikea CEO Says Greenwashing Less Dangerous than Silence on Climate. Bloomberg Green, 10 November 2021. Available online: https:/ / www.bloomberg.com/news/articles/2021-11-09/ikea-at-cop26-ceo-urges-transparency-action-onclimate-change(accessed on 24 December 2021).

27. White, K.; Hardisty, D.J.; Habib, R. The Elusive Green Consumer. Harvard Business Review, July-August 2019. 124-133. Available online: https:/ / hbr.org/2019/07/the-elusive-green-consumer(accessed on 11 November 2021).

28. Bigliardi, B.; Campisi, D.; Ferraro, G.; Filippelli, S.; Galati, F.; Petroni, A. The Intention to Purchase Recycled Products: Towards an Integrative Theoretical Framework. Sustainability 2020, 12, 9739. [CrossRef]

29. Skard, S.; Jørgensen, S.; Pedersen, L.J.T. When is Sustainability a Liability, and When Is It an Asset? Quality Inferences for Core and Peripheral Attributes. J. Bus. Ethics 2021, 173, 109-132. [CrossRef] 
30. Jørgensen, S.; Pedersen, L.J.T.; Skard, S. How consumers perceive sustainable products. LSE Blog, 14 February 2020. Available online: https://blogs.lse.ac.uk/businessreview/2020/02/14/how-consumers-perceive-sustainable-products / (accessed on 30 October 2021).

31. Pheifer, A. Barriers and Enablers to Circular Business Models; ValueC: Brielle, The Netherlands, 2017; Available online: https: //www.circulairondernemen.nl/uploads/4f4995c266e00bee8fdb8fb34fbc5c15.pdf (accessed on 22 October 2021).

32. Fotiou, S.; Cox, A. The Price of Plastic Waste and Solutions to Turn the Tide. United Nations ESCAP, 29 January 2021. Available online: https:/ / www.unescap.org/blog/price-plastic-waste-and-solutions-turn-tide(accessed on 20 December 2021).

33. DeWit, W.; Burns, E.T.; Guinchard, J.-C.; Ahmed, N. Plastics: The Costs to Society, the Environment, and the Economy; World Wide Fund for Nature: Gland, Switzerland, 2021.

34. Helbling, T. Externalities: Prices Do Not Capture All Costs; International Monetary Fund: Washington, DC, USA, 2020; Available online: https:/ / www.imf.org/external/pubs/ft/fandd/basics/external.htm (accessed on 24 September 2021).

35. OECD. Assessing and unlocking the circular economy in Groningen, Netherlands. In The Circular Economy in Groningen, the Netherlands; OECD Publishing: Paris, France, 2020. [CrossRef]

36. Kahneman, D.; Tversky, A. Prospect Theory: An Analysis of Decision under Risk. Econometrica 1979, 47, 263. [CrossRef]

37. Cha, V. Episode 008: Professor Virginia Cha: Coping with a Hyperconnected World. Red Team Thinking, 4 October 2021. Available online: https://www.redteamthinking.com/podcast/virginia-cha(accessed on 5 October 2021).

38. Arkes, H.R.; Blumer, C. The psychology of sunk cost. Organ. Behav. Hum. Decis. Process. 1985, 35, 124-140. [CrossRef]

39. Ranta, V.; Aarikka-Stenroos, L.; Ritala, P.; Mäkinen, S.J. Exploring institutional drivers and barriers of the circular economy: A cross-regional comparison of China, the US, and Europe. Resour. Conserv. Recycl. 2018, 135, 70-82. [CrossRef]

40. Zhang, A.; Venkatesh, V.G.; Liu, Y.; Wan, M.; Qu, T.; Huisingh, D. Barriers to smart waste management for a circular economy in China. J. Clean. Prod. 2019, 240, 118198. [CrossRef]

41. Staicu, D.; Pop, O. Mapping the interactions between the stakeholders of the circular economy ecosystem applied to the textile and apparel sector in Romania. Manag. Mark. 2018, 13, 1190-1209. [CrossRef]

42. Ferronato, N.; Torretta, V. Waste Mismanagement in Developing Countries: A Review of Global Issues. Int. J. Environ. Res. Public Health 2019, 16, 1060. [CrossRef] [PubMed]

43. Kirchherr, J.; Piscicelli, L.; Bour, R.; Kostense-Smit, E.; Muller, J.; Huibrechtse-Truijens, A.; Hekkert, M. Barriers to the Circular Economy: Evidence From the European Union (EU). Ecol. Econ. 2018, 150, 264-272. [CrossRef]

44. Nelles, M.; Grünes, J.; Morscheck, G. Waste Management in Germany—Development to a Sustainable Circular Economy? Procedia Environ. Sci. 2016, 35, 6-14. [CrossRef]

45. Melati, K.; Nikam, J.; Nguyen, P. Barriers and Drivers for Enterprises to Transition to Circular Economy; Stockholm Environment Institute: Stockholm, Sweden, 2021.

46. Garcés-Ayerbe, C.; Rivera-Torres, P.; Suárez-Perales, I.; Leyva-De La Hiz, D. Is It Possible to Change from a Linear to a Circular Economy? An Overview of Opportunities and Barriers for European Small and Medium-Sized Enterprise Companies. Int. J. Environ. Res. Public Health 2019, 16, 851. [CrossRef] [PubMed]

47. Araujo Galvão, G.D.; De Nadae, J.; Clemente, D.H.; Chinen, G.; De Carvalho, M.M. Circular Economy: Overview of Barriers. Procedia CIRP 2018, 73, 79-85. [CrossRef]

48. Wojnowska-Baryła, I.; Kulikowska, D.; Bernat, K. Effect of Bio-Based Products on Waste Management. Sustainability 2020, 12, 2088. [CrossRef]

49. Hart, J.; Adams, K.; Giesekam, J.; Tingley, D.D.; Pomponi, F. Barriers and drivers in a circular economy: The case of the built environment. Procedia CIRP 2019, 80, 619-624. [CrossRef]

50. Ritzén, S.; Sandström, G.Ö. Barriers to the Circular Economy-Integration of Perspectives and Domains. Procedia CIRP 2017, 64, 7-12. [CrossRef]

51. Ritala, P. Innovation for Sustainability: Sceptical, Pragmatic, and Idealist Perspectives on the Role of Business as a Driver for Change. In Palgrave Studies in Sustainable Business In Association with Future Earth; Springer International Publishing: New York, NY, USA, 2019; pp. 21-34. [CrossRef]

52. Boey, A. Green buildings: Not Enough? Available online: https://www.siew.gov.sg/articles/detail/2012/08/12/green-buildingsnot-enough (accessed on 21 December 2021).

53. Caldera, H.T.S.; Desha, C.; Dawes, L. Evaluating the enablers and barriers for successful implementation of sustainable business practice in 'lean' SMEs. J. Clean. Prod. 2019, 218, 575-590. [CrossRef] 